Revista de la red interuniversitaria de estudios sobre las literaturas rioplatenses contemporáneas en Francia

$9 \mid 2013$

Homenaje a Ana María Barrenechea

\title{
Cosa de locas : las lenguas de Néstor Perlongher
}

\section{Jorge Panesi}

\section{OpenEdition}

\section{Journals}

Edición electrónica

URL: http://journals.openedition.org/lirico/1139

DOI: 10.4000/lirico.1139

ISSN: 2262-8339

Editor

Réseau interuniversitaire d'étude des littératures contemporaines du Río de la Plata

\section{Referencia electrónica}

Jorge Panesi, «Cosa de locas : las lenguas de Néstor Perlongher », Cuadernos LIRICO [En línea],

9 | 2013, Puesto en línea el 01 septiembre 2013, consultado el 30 abril 2019. URL : http:// journals.openedition.org/lirico/1139; DOI : 10.4000/lirico.1139

Este documento fue generado automáticamente el 30 abril 2019.

\section{cc) ()요}

Cuadernos LIRICO está distribuido bajo una Licencia Creative Commons Atribución-NoComercialSinDerivar 4.0 Internacional. 


\title{
Cosa de locas : las lenguas de Néstor Perlongher
}

\author{
Jorge Panesi
}

1 A veces la lengua se vuelve loca. $\mathrm{O}$ al menos eso creía Derrida. Salvo que la locura de esa loca está desde siempre allí, como un agente que actuará tarde o temprano en el momento menos pensado, y también y sobre todo, en todos los momentos. La regularidad de los versos, su recursividad regulada parece lo contrario de la locura, pero justamente, los esquemas de la razón esconden monstruos. Cuando una lengua se vuelve loca deja salir a los monstruos, los desata, los desvela; cuando una lengua se vuelve loca son las locuras del mundo las que combaten con ella. Cuando una lengua se vuelve loca pueden acudir todos los artificios barrocos y con ellos el chillido de las locas que están siempre al borde de parodiar su propia monstruosidad. Una vez interrogué a Néstor Perlongher acerca de un diferendo, una polémica intelectual de la que había participado, y me respondió : "No hagas caso. Es cosa de locas".

Obedezco, pero creo que hay una encrucijada, un nudo en esa expresión "cosa de locas": él supo hacer una política no sólo con lo suburbano, lo minoritario y lo lumpen, sino que le dio una dimensión poética a la lengua de las locas. Perlongher: hacer con toda deliberación que la lengua enloquezca, pero hacer también que la poesía definitivamente hable la lengua de las locas, que es muy otra cosa que la consabida identidad nómade del género, o esas serias manifestaciones programáticas que pueblan y etiquetan la jerga crítica con que se aborda a Perlongher desde hace veinte años. No estoy juzgando la eficacia del profuso discurso que ha recibido su obra, sino la relación que la crítica misma mantiene con esa lengua que, con una porosidad inaudita para la poesía argentina, da un golpe inesperado en el rumbo de su historia. Lengua de las locas, las locas nunca pudieron hablar así en la poesía, y los intentos anteriores en toda Latinoamérica se convierten en recatados gestos pudibundos y culposos que sólo ensalzan la moral establecida, la trampa cuyo mecanismo se padece. No es solamente que Lezama, Góngora o el modernismo rubeniano posibilitaran (como de hecho lo hacen) el enloquecimiento de la poesía de 
Perlongher, sino que Austria-Hungría o Alambres permiten avizorar o paladear lo que de locas tenían los amaneramientos de esos discursos anteriores.

Cuando una lengua cambia, no es sólo la lengua la que cambia. Son la historia misma y el entrecruzamiento de sus procesos los que están siempre enloqueciendo. Sería pueril desear que la crítica literaria o los que se dedican a hurgar y establecer los cuadros o los mapas con los que se ha de pensar históricamente la poesía argentina mimetizaran la lengua de su objeto, y sin embargo, algo de la objetividad académica debe haber cambiado, si bien no en la materialidad misma con la que se escribe, al menos en la panoplia conceptual a la que esa lengua estudiada da lugar, o al combate de posiciones y de lenguajes heteróclitos que asomaban entre los versos de la tradición barroca. $\mathrm{Si}$, como creo, la irrupción de Perlongher produce una serie de efectos inesperados en la poesía argentina, más allá de las etiquetas -barroco, neobarroco, neobarroso- que los grupos poéticos necesitan para hablar de sí mismos y para establecer sus poéticas, es lógico pensar que también esa poesía, entre sus alcances, haya producido algo que repercutió en la lengua de la crítica. Hace ahora bastante tiempo, Martín Kohan en un congreso reprochaba a los críticos de entonces (supongo que yo estaba incluido) que nos hubiésemos mimetizado con la lengua de Perlongher, esto es, el no haber guardado la debida distancia con la poesía que abordábamos, y que hubiésemos embarrado nuestra lengua con el limo de esos versos tan idiosincrásicos. Puede ser cierto, aunque no sé si mi prosa cedió a la fuerza encantatoria del discurso que debía desentrañar, o si se trataba precisamente de la lengua en la que ciertos poetas logran hacerse sentir más allá de sí mismos, de la poesía que escriben y de los círculos sociales en los que se mueven. Son cimbronazos efectuados con la lengua. El modernismo y la lengua de Rubén Darío, además de ser capítulos en las historias de la literatura, en su contexto de origen tuvieron el efecto de cimbronazos : cambiaron la sensibilidad con que los lectores se acercaban a la poesía, pero además provocaron una alteración quizá menos perceptible, aunque de todos modos rastreable, en el discurso crítico. De hecho, el objeto de la crítica obliga al discurso que se ocupa de él, lo obliga al juicio, que no es otra cosa que una cierta distancia empática o de lejanía históricamente variable y determinable.

4 Y son dos las historias que la crítica ha intentado contar acerca de Perlongher, dos historias que no siempre coinciden, aunque cada una de ellas esté obligada a mentar o considerar a la otra. Como si estuvieran en la certeza de su propia incompletud, como si reconociesen de antemano que van a simplificar engañosamente la narración explicativa. Una es la historia de la poesía argentina y el lugar dado al neobarroco, o la diferenciación poética que supone lo que Perlongher llamó "neobarroso" : aquí la faceta de agitador político no se olvida, pero tiene escaso relieve en un relato por momentos demasiado cerrado sobre sí mismo y sobre los menudos avatares (algunos excesivamente narcisistas) con los cuales los protagonistas de la poesía argentina sazonan su propia historia. La otra historia que se cuenta de Perlongher se centra en sus luchas políticas e identitarias, y la referencia a su poesía es también obligada, aunque pocas veces se intenta aclarar qué valor tiene o cómo llega a producirse lo que él hubiese denominado "un agenciamiento político-poético". Advierto que no me gusta la palabra "militante" que suele usarse para estos casos, y que le sienta menos que a ninguno: prefiero la expresión que usan Baigorria y Ferrer en su prólogo ${ }^{1}$ a Prosa plebeya, "agent provocateur", porque como provocador lo que logra poner de relieve es la jerarquización policíaco-militar de las facciones políticas y de la "militancia". 
5 Las dos historias, la del provocador político y la del poeta, otorgan a Perlongher un lugar preponderante en cada una de las tramas, una especie de sitio inobjetable al que las resistencias y las solapadas objeciones, en su timidez, no logran derruir. Y es en la poesía, en la emergencia del neobarroco en las riveras del Plata, donde las reticencias y los atajos valorativos son más fuertes y abundantes.

6 Una obra que tiene a la trinchera, la guerra o la lucha como metáforas privilegiadas, estaba destinada a que surgiese en medio de una oposición que ya forma parte casi canónica de esa historia : un saludo al barroco (el de Nicolás Rosa²), y una acre valoración no menos belicosa hacia el grupo de poetas neobarrocos (la de Daniel García Helder desde Diario de poesía en 1987). En García Helder, Perlongher desaparece en medio del grupo formado por Piccoli, Carrera, Sarduy, Kamenszain y los poetas que aparecieron en la revista Xul, un grupo dedicado a la frivolidad y el hermetismo injustificado de una secta extranjerizante (sentencia García Helder) que muere por las novedades de París y de Tel Quel. Tiene razón Ana Porrúa cuando relata este diferendo ${ }^{3}$ : hay en García Helder un enorme fastidio por el modo poético de este grupo, sin embargo García Helder nos dice que le gustan poemas sueltos de los neobarrocos, y en el caso de Perlongher prefiere "El cadáver", y “no ese otro poema 'Cadáveres”', lo que nos indica que en 1987 este último ya ha comenzado a ser la síntesis político-poética que condensa y cierra una época tenebrosa. Cuestión de grupos, de posiciones reactivas, fastidios y rivalidades. Lo cierto es que junto con el neobarroco nace, como un contrapunto, otra tendencia nucleada en Diario de poesía, el llamado objetivismo, con concepciones de la lengua, el signo, y el referente, totalmente divergentes. Como si la identidad de ambos grupos se jugase en ese contrapunto. Los gastos de la batalla corren a cuenta de los objetivistas nucleados en el Diario que rechazan y censuran el neobarroco cuyos integrantes no polemizan ni contestan (Porrúa 2003). Sintetizando los años de la dictadura militar, en 1993 Daniel Freidenberg (otro integrante de Diario de poesía), también celebra la importancia del poema Cadáveres de Perlongher, pero cree en una conspiración entre neobarrocos, críticos universitarios y periodistas, que denomina "fenómeno periodístico-cultural del neobarroco [...], un aparato de teóricos, críticos y periodistas de algunos medios culturales" (Freidenberg 1993). Está claro que los gestos interpretados como tendencia a la hegemonía (ése es el sentido de la "conspiración" que ve Freidenberg) tiende a aplanar y poner en segundo plano la diversidad de las voces y las tendencias poéticas. Se trata entonces de que el neobarroco no ocupe toda la escena, y de dar en el hilo histórico mayor visibilidad a otros grupos, en particular a quienes, paradójicamente, como los objetivistas, rechazan por superficiales e inútilmente herméticos a sus rivales, que con este hostigamiento adquieren una unidad identificatoria y un reconocimiento polémico a regañadientes. Mucho más tarde, ya en la primera década del siglo XXI, la convivencia (inclusive dentro de Diario de poesía) muestra que unos y otros se sienten parte de una historia en la que son partícipes opuestos y dialécticos : se impugnan constitutivamente porque ambos se constituyen en la impugnación. Reeditan inesperadamente a Florida y Boedo, salvo que ahora son dos facciones que habitan el mismo barrio.

7 Esto se desprende de la historización interesada que realiza en el año 2006 Martín Prieto atento al calembour con el que siempre juega la historia (Prieto 2007) : luego de Onganía se esperaba una poesía que descendiera de Gelman, el coloquialismo y la poesía de los sesenta, pero en cambio apareció un grupo que "hacía base" en la revista Literal. Lo que no quiere decir -afirma Prieto- que la política estuviera ausente, como lo prueba Cadáveres de Néstor Perlongher (¿y por qué estaría ausente la política?- me pregunto yo). 
Prieto celebra que la biblioteca neobarroca sea "eminentemente nacional y abierta a al diálogo y a la conversación y a la confrontación con una biblioteca latinoamericana, diálogo que históricamente la literatura argentina después del Modernismo prefirió no mantener" (Prieto 2007 : 27). Prieto empareja a neobarrocos y objetivistas, en varios rasgos, entre ellos el rechazo a la poesía de Gelman, y la coincidencia en revalorizar a otros poetas como Leónidas Lamborghini. Con el correr del tiempo, en la fábula de este relato, objetivistas y neobarrocos, según Prieto, tendrán enemigos comunes que habrán de impugnar una consagración que ambos grupos comparten en el reciente panteón del canon. Lo cierto es que Perlongher atraviesa indemne los "fastidios" y las "reticencias" de sus contemporáneos, y hacia fines de la década de los noventa, poco menos que intocable, es uno de los referentes obligados de los jóvenes, según se desprende del relato de Edgardo Dobry, ligado al Diario de poesía: "su gesto irreductiblemente provocativo, su lengua llena de escatología y erotismo crudo, su 'juego' con el habla popular lo convierten en uno de los claros antecedentes de los objetivistas de los noventa" (Dobry 1999: 52). Desde el lado neobarroco, el bucle se cierra con un gesto de hastío, el de Tamara Kamenszain, que prefiere adosar a la cadena barroco-neobarroco-neobarroso, el de neo borroso, porque el de Perlongher fue "un intento por manchar de barro -pero sobre todo de barrio- un concepto que se empezaba a estereotipar tornándose cada vez más funcional a la crítica", y citando "Cansancio" de Girondo, sintetiza : "ahora tal vez yo me afiliaría a un movimiento que bien podría llamarse neoborroso" (Kamenszain 2010). ${ }^{4}$

No menos complicados son los avatares con los que se narra la provocación de Perlongher en el campo de las reivindicaciones de homosexuales, lesbianas, travestis y transexuales. Aquí, en esta trama, Perlongher es tanto el precursor, el avanzado, como el que preanuncia las encrucijadas del porvenir y los desarrollos de la teoría queer. Tampoco esta historia se narra sin objeciones ni reticencias como las que formula Flavio Rapisardi cuando reseña la irrupción intransigente de Perlongher en un segundo tiempo del pionero Frente de Liberación Homosexual :

Entre los/as integrantes de esta segunda ola, la personalidad y la capacidad arrolladora de Perlongher se impondrían hasta casi identificar al FLH con su persona. Y esto no es metáfora. Él solo, con su solo juicio, llegó a decidir la permanencia de compañeros/as en las filas del movimiento: sus posturas antijerárquicas muchas veces no lo incluían. (Rapisardi 2008)

Es en esta articulación entre políticas libertarias de los grupos minoritarios segregados y las políticas de la izquierda argentina donde se produce el efecto más radical e innovador que convierte a Perlongher en un vaticinio de las futuras estrategias de los movimientos de diversidad sexual y de género. Dice muy bien Javier Gasparri : "Perlongher trabaja con la suma de saberes actuales de sus años, pero también contiene en potencia lo que vendrá". ${ }^{5}$ ¿Qué cualidad o don es el que otorga a Perlongher poeta o provocador político la capacidad de estar más allá del cerco de su presente ? Creo que, en primer lugar, este don tiene que ver con su desconfianza hacia la consolidación de la palabra oficial, o para ser más exactos, de las palabras oficiales que se estratifican como jerarquías en los grupos políticos contestatarios, o son directamente la voz de la jerarquía en esos grupos. La mirada de Perlongher es siempre una mirada desde abajo, la mirada que desanda y destruye el empinamiento del orden jerárquico allí donde éste se forma o se solaza. Por eso no es anecdótica su mordaz polémica con los intelectuales que han apoyado a los militares en la suicida guerra de las Malvinas, cuando el orden de la dominación coincidía con el asesino interés del Estado. ${ }^{6}$ Es el machismo visceral de los militares o de los militantes de izquierda, el que siempre se recompone y resurge, no como un agregado 
periférico inocuo de la política, sino como un rasgo esencial de su accionar. La loca y la lengua de la loca, más que replicar en negativo el machismo al que se subordinaría, es la provocación que se ríe tanto de la fuerza del dominio como de su propia y aparente fragilidad frente al dominador.

En segundo lugar, hay en los atribulados vaticinios de Perlongher una percepción muy aguda de las fuerzas históricas que se agitan en los remolinos de su horizonte : desdeña lo que se estanca o gelifica, lo que se territorializa, y por esta misma conciencia, está siempre pendiente del movimiento y el devenir. En el momento en que sale el libro sobre el miché, ya plantea su estudio como un momento pasajero, un estado arqueológico del deseo masculino paulista destinado a desaparecer por la medicalización que arrastra el Sida y el deslizarse hacia un modelo "gay" que destrona la polaridad loca/chongo, lo que Perlongher llama "la muerte de la homosexualidad", vale decir, su disolución o indiferenciación en el cuerpo social ("...los gays a la moda norteamericana, de ergidos bigotitos hirsutos, desplomándose en su condición de paradigma individualista en el más abyecto tedio - un reemplazo del matrimonio normal que consigue la proeza de ser más aburrido que éste -") $)^{7}$. Perlongher historiza siempre, no sólo el legendario Frente de Liberación Homosexual del que formó parte, sino que pone el presente en la duda sobre qué fuerzas se agenciarán en el futuro : si la homosexualidad perdió su carga disruptiva, es la droga - sostiene- la que ahora preocupa a los Estados y las policías. La mística y la droga producen en la cultura el efecto contrario a la normalización del esquema individualista gay : es el salir de sí, la fuga o el puro gasto a la manera de Bataille. Cuando comenta Alambres 8 , es la historia y el deseo los que se unen en una "épica barroca, donde la historia es deseada, alucinada en el deseo". En la poesía, la historia se pone a delirar; poesía e historia alucinan, deliran juntas en una condensación corporal, o según lo dice él mismo : "se trata en el plano de la escritura de hacer un cuerpo". ("Sobre Alambres", 140)

11 Si la poesía es en la definición de Perlongher "un ramo del éxtasis" ("Sobre Alambres", 140), entonces la multiplicidad y la heterogeneidad de su proyecto tienen en la lengua poética que de allí surge, no un sistema, no un resumen, no una totalidad y una jerarquía, sino un hilo que permite enhebrar la lectura, más allá de los géneros, y el privilegio de un género sobre otro. No se podría abordar su obra de otra manera, sin separar la poesía del ensayo o el relato, no se la podría abordar por migajas o retazos, por más que en apariencia ésta sea la modalidad que la obra solicita. Porque también solicita el delirio, solicita que la crítica delire con ella, que se someta al delirio de esa lengua, y frente a esta demanda, la crítica que la sigue está obligada a razonar el delirio. Me parece que si la lectura fundante de Nicolás Rosa nos enseñó a leer a Perlongher, si ha sido una lectura potente y magnífica, su poder reside todavía en que ha sabido delirar junto a su objeto, esto es, delirar y razonar junto con Perlongher. Porque sin mimetizarse con él, la prosa de Nicolás Rosa es barroca, excesiva y proliferante, da a leer el exceso y la heterogeneidad, al mismo tiempo que le agrega el deslinde y la reflexión a la reflexión que ya es la actitud poética delirante. Para Rosa, Perlongher es ante todo "un artesano de la locura lingüística" (2002: 24).

Desde otra perspectiva, esta vía sintética, textual y cultural a la vez, es la que coloca a Perlongher en tramas más vastas, más ligadas al desarrollo de esas mismas puntas culturales y lingüísticas que él comenzó a andar. Es lo que hace Cecilia Palmeiro en Desbunde y felicidad (2011), preocupada por seguir el trazo de Perlongher más allá de sus propios límites temporales, teóricos, textuales y de acción política. Palmeiro sabe leer en la dispersión hacia distintos ámbitos la persistencia de una huella que se desborda a sí 
misma. Porque eso es lo que Perlongher entiende por "delirio" o "locura" : el salirse de sí, como el sistema poético de Lezama Lima, que alucinando historia y literatura sustituye a la religión. Si hay un ímpetu religioso en Perlongher es ese afán de desborde que puja por salirse de sí, por salir de sí y perderse en una incognoscible fusión. El barroco de Lezama dice Perlongher- es una divinidad de "una demencia incontenible" que tiene "cierta disposición al disparate" y que apunta "al nódulo del sentido oficial de las cosas". Con lo que, el delirio o la locura, en su desarreglo, atacan la jerarquía establecida de los órdenes culturales y sociales. Si hay una política que atraviesa toda la acción de Perlongher ésta es la de una actitud anárquica, la no sumisión por principio ni a las jerarquías, ni a los discursos o las políticas oficiales.

13 La proliferación barroca del sentido, la lateralidad manifiesta de los significados poéticos enloquecen deliberadamente mediante una profusión periférica que normalmente el discurso serio reprime y subsume en el establecimiento de jerarquías semánticas. Por eso, la microfísica del poder se corresponde en Perlongher con una microfísica de la acción lingüística. El barroquismo es el garante para que ese desarreglo lingüístico se produzca, un ataque a la lengua como orden idealizado, como el agente solapado u ostensible del nacionalismo reaccionario. En Francia asiste al culto de la pureza y la jerarquía de la lengua francesa, un culto religioso esencialista y narcisista de la lengua propia :

... aquí en la Argentina a nadie se le ocurriría amar el español, decir como un elogio que alguien tiene un buen español. ¡En Francia el francés es lo máximo! Decir que alguien tiene buen francés, es el máximo elogio, al borde de la perpetua beatificación. [...] Es una lengua de élite, una lengua de poder, la lengua como instrumento de poder y de dominación.

O, para decirlo con Adrián Cangi (2009 : 9), "[la literatura] comienza cuando el poeta a fuerza de insistencia produce una lengua contra la lengua, una escritura contra la escritura". "Crueldad" llama también Cangi a esta acritud polémica que disuelve cualquier falsa esperanza idealista $Y$ en esta disolución ha consistido todo el empeño de Perlongher.

construcción de una lengua hiperbólica y excesiva pudo parecer en el momento en que surgía, como un gesto injustificado, un lujo sin fundamento, o un jugueteo bizantino, intrascendente, con la materia significante. Pero nada vano hay en el volverse loca de la lengua de Perlongher. Ahora sabemos que a semejante locura la estábamos esperando como una necesidad de la historia.

El principio que encontramos en ese cimbronazo es el de la contaminación generalizada, porque lo que se contamina, lo que se intercambia, anula la jerarquización. La jerarquía siempre instaura una distancia que permite el dominio y el sometimiento, en cambio, el principio de contaminación lingüística (que es la acción de la lengua misma fuera de sus usos jerárquicos o de dominación) mezcla, perturba la clasificación establecida, afecta las polaridades, y se afecta a sí misma en la contaminación. Y la lengua de Perlongher se deja afectar por este principio : el barroquismo no es patrimonio exclusivo de la poesía, avanza hacia el relato y el ensayo. Y toda la obra de Perlongher, la poética, la ensayística, la narrativa, la del investigador social, la del agitador, se halla afectada por la contaminación, no otra cosa es lo barroso del barroco.

La lengua se enloquece (o se "emputece" como le gusta decir a Cecilia Palmeiro), y lo hace desde "abajo", contamina la idealización, el estereotipo, los flecos del mito político (como en Evita vive) desde el registro popular, desde las hablas de los márgenes, las locas y los chongos, mezclados con el decir de la teoría o la filosofía de Deleuze-Guattari, que se 
avienen en la contaminación a ser en un habla más entre las hablas, aunque, sin embargo, en Perlongher mantienen una adhesión explicativa llena de fervor teórico y emancipador. En "Nueve meses en París", Deleuze-Guattari son presentados por Perlongher como lo marginal de "una cultura completamente cerrada sobre sí, unos feudos más cerrados que una concha", y el Antiedipo como un texto inasimilable para la cultura francesa que "es objeto de una execración generalizada".

Salvo que aquí tampoco Deleuze-Guattari se salvan de la crueldad, pues, nos advierte, “... en Mil Mesetas ellos se juegan a la desterritorialización a la violeta".

Para Perlongher, lo contrario del delirio es el mito. La acción política bordea lo mítico, lo usa, trabaja para alcanzar la máxima eficacia cuando su forma o su contenido se convierten en mito. En este sentido, los delirios de Perlongher son anti-mitos que se construyen con la misma substancia que emplea la acción política, pero para destruirla desde adentro, con su propio mecanismo hipertrofiado, sexualizado, lumpenizado. El delirio es eficaz porque escapa, huye, no forma centro ni se estratifica, es difícil de asir y resiste los embates del silogismo.

La lengua se ha vuelto loca para desestabilizar el mundo y dar vuelta la historia. Pero como figura, las locas han coqueteado siempre con la autodestrucción y la muerte, han jugueteado con la risa de la calavera. Perlongher siempre lo ha sabido y lo ha dicho, lo ha repetido hacia el final, en Chorreo de las iluminaciones, en un poema que titula "Gemido" :

reírse como locas (locas, locas) del tiempo de las otras lo-

cas, del dolor de las locas y del loco dolor de la locura.

[...]

al verlas marchitarse exasperadamente entre los vastos ademanes de la histeria [...],

disminuyendo día a día la distancia que las separa de lo trágico

y las acerca a lo ridículo, a lo kitsch

las locas

desaparecen por cañerías de acero que no llevan a nada

o al sitial de las profanaciones de los zombies

en la noche agrisada por sus centauros. (Perlongher 1993 : 349-351)

\section{BIBLIOGRAFÍA}

\section{Obras citadas}

Cangi, Adrián. "Néstor Perlongher : metamorfosis, crueldad, dislocamientos". En : Néstor

Perlongher. Evita vive y otros relatos. Buenos Aires : Santiago Arcos, 2009.

Dobry, Edgardo. "Poesía argentina actual : del neobarroco al objetivismo". En : Cuadernos

Hispanoamericanos, n588, junio 1999.

Freidenberg, Daniel. "Poesía argentina de los años 70 y 80. La palabra a prueba". En : Cuadernos

Hispanoamericanos, $\mathrm{n}^{\circ}$ 517-510, junio-setiembre 1993.

Gasparri, Javier. "Perlonguer en la trinchera : sexualidad y afección". VI Congreso Internacional de

Estudios sobre a Diversidade Sexual e de Gênero da ABEH. 
Kamenszain,Tamara. “Neobarroco, neobarroso, neoborroso". En revista Ñ, Diario Clarín, sábado 1 de abril de 2010.

Kamenszain,Tamara. “Testimoniar sin metáfora. La poesía argentina de los 90”. En : La boca del testimonio. Buenos Aires : Norma, 2007.

Palmeiro, Cecilia. Desbunde y felicidad. De la Cartonera a Perlongher. Buenos Aires : Título, 2011.

Perlongher, Néstor. Poemas completos (1980-1992). Buenos Aires : Seix Barral, 1993.

Perlongher, Néstor. Prosa plebeya. (Ensayos 1980-1992). Selección y prólogo de Christian Ferrer y Osvaldo Baigorria. Buenos Aires : Colihue, 2008.

Perlongher, Néstor. Evita vive y otros relatos. Buenos Aires : Santiago Arcos, 2009.

Porrúa, Ana. "Una polémica a media voz : objetivistas y neo-barrocos en el Diario de poesía". En : Boletín/11 del Centro de Estudios de Teoría y Crítica Literaria (Univ. Nacional de Rosario), diciembre de 2003.

Porrúa, Ana. "La novedad en las revistas de poesía : relatos de una tensión especular". En : Orbis Tertius, (Univ. Nacional de La Plata), X, 11, 2005.

Prieto, Martín. “Neobarrocos, objetivistas, epifánicos y realistas : nuevos apuntes para la historia de la nueva poesía argentina". En Delgado, Sergio y Premat, J. (editores). Movimiento y nominación. Notas sobre la poesía argentina contemporánea. En : Cahiers de LI.RI.CO, $\mathrm{n}^{\circ} 3$, Université de Paris 8Université de Bretagne-Sud, 2007, pp. 23-44.

Rapisardi, Flavio. "Escritura y lucha política en la cultura argentina : identidades y hegemonía en el movimiento de diversidades sexuales entre 1970 y 2000". En : Revista Iberoamericana (Pittsburgh), vol. LXXIV, n²25, octubre-diciembre 2008, pp. 973-995.

Rosa, Nicolás. "Prólogo”. En : Héctor A. Piccoli. Si no a enhestar el oro oído. Rosario : La Cachimba, 1983.

Rosa, Nicolás. Los fulgores del simulacro. Santa Fe : Universidad Nacional del Litoral, Departamento de Extensión Universitaria, 1987.

Rosa, Nicolás. “De estos polvos, estos lodos...”. En : Cuadernos de Recienvenido/18 (São Paulo), 2002.

\section{NOTAS}

1. En : Néstor Perlongher, Prosa plebeya. (Ensayos 1980-1992) (2008).

2. Nicolás Rosa, "Prólogo" a : Héctor A. Piccoli, Si no a enhestar el oro oído (1983). Véase también su “Seis tratados y una ausencia sobre los “Alambres' y rituales de Néstor Perlongher”, en : Los fulgores del simulacro (1987).

3. Ana Porrúa, "Una polémica a media voz: objetivistas y neo-barrocos en el Diario de poesía" (2003). Véase también de Ana Porrúa: "La novedad en las revistas de poesía : relatos de una tensión especular" (2005)

4. Imprescindible para esta historia es otro trabajo de Kamenszain, "Testimoniar sin metáfora. La poesía argentina de los 90" (2007).

5. Javier Gasparri, "Perlongher en la trinchera : sexualidad y afección".

6. Ver Néstor Perlongher, “Todo el poder a Lady Di”, "La ilusión de unas islas", "El deseo de unas islas", en Prosa Plebeya (2008).

7. Néstor Perlongher, "Avatares de los muchachos de la noche", en Prosa Plebeya.

8. “Sobre Alambres", en El Porteño n 74, febrero de 1988, recogido en Prosa Plebeya. 
9. Néstor Perlongher, "Caribe transplatino", en Prosa plebeya.

\section{RESÚMENES}

La lengua de la obra de Néstor Perlongher cambia la historia de la poesía argentina. Después de pasar en revista los principales relatos críticos que se han construido acerca de ella, el ensayo aborda la excepcional capacidad provocadora de la escritura de Perlongher y el carácter anticipatorio de su lenguaje. El autor considera en particular dos puntos : la destrucción de todo orden jerárquico, incluido el de la semántica, que es característica de la mirada de Perlongher, y su elección de una poética del desborde y la contaminación. El gesto radical de su poesía sigue requiriendo un lenguaje crítico que no eluda el exceso y la heterogeneidad de su objeto y que sea capaz de delirar junto con él.

La langue de l'oeuvre de Néstor Perlongher change l'histoire de la poésie argentine. Après avoir passé en revue les principales orientations de la critique à son sujet, l'essai interroge l'exceptionnelle capacité de provocation de l'écriture de Perlongher ainsi que la nature anticipatoire de son langage. L'auteur développe notamment deux points, à savoir: la destruction de toute hiérarchie -y compris sémantique- caractéristique du point de vue de Perlongher, et son choix d'une poétique du débordement et de la contamination. Ce geste radical de sa poésie demande toujours un langage critique qui n'évite ni l'excès ni l'hétérogénéité de son objet mais accepte, au contraire, de délirer à son image.

The language of Néstor Perlongher's work changes the history of Argentine poetry. After reviewing the main critical trends on it, the essay studies the writer's exceptional provoking capacity and anticipatory language nature. The author sustains two main points : the destruction of any -including semantics - hierarchy, characteristic of Perlongher's viewpoint, and his choice of a trespassing and contamination poetics. That radical gesture of his poetry still asks for a critical language avoiding neither excess nor heterogeneity and adopting part of the frenzy and madness of its object.

\section{ÍNDICE}

Mots-clés: Perlongher, délirante, poétique de la contamination, langue (de) folle, hétérogénéité

Keywords: delirious, poetics of contamination, gay/mad language, heterogeneity

Palabras claves: poética de la contaminación, lengua (de) loca, heterogeneidad

\section{AUTOR}

\section{JORGE PANESI}

Universidad de Buenos Aires 